\title{
Metabolic responses to pyruvate kinase deletion in lysine producing Corynebacterium glutamicum Judith Becker ${ }^{1}$, Corinna Klopprogge ${ }^{2}$ and Christoph Wittmann*1
} Address: ${ }^{1}$ Biotechnology Department, Institute for Biochemistry, Westfalian Wilhelms University Münster, Germany and ${ }^{2}$ BASF AG, Research Fine
Chemicals and Biotechnology, Ludwigshafen, Germany

Email: Judith Becker - judith.becker@uni-muenster.de; Corinna Klopprogge - corinna.klopprogge@basf.com; Christoph Wittmann* - c.wittmann@uni-muenster.de

* Corresponding author

Published: I3 March 2008

Microbial Cell Factories 2008, 7:8 doi:10.1 186/1475-2859-7-8
Received: 28 September 2007

Accepted: 13 March 2008

This article is available from: http://www.microbialcellfactories.com/content/7///8

(C) 2008 Becker et al; licensee BioMed Central Ltd.

This is an Open Access article distributed under the terms of the Creative Commons Attribution License (http://creativecommons.org/licenses/by/2.0), which permits unrestricted use, distribution, and reproduction in any medium, provided the original work is properly cited.

\begin{abstract}
Background: Pyruvate kinase is an important element in flux control of the intermediate metabolism. It catalyzes the irreversible conversion of phosphoenolpyruvate into pyruvate and is under allosteric control. In Corynebacterium glutamicum, this enzyme was regarded as promising target for improved production of lysine, one of the major amino acids in animal nutrition. In pyruvate kinase deficient strains the required equimolar ratio of the two lysine precursors oxaloacetate and pyruvate can be achieved through concerted action of the phosphotransferase system (PTS) and phosphoenolpyruvate carboxylase (PEPC), whereby a reduced amount of carbon may be lost as $\mathrm{CO}_{2}$ due to reduced flux into the tricarboxylic acid (TCA) cycle. In previous studies, deletion of pyruvate kinase in lysine-producing $C$. glutamicum, however, did not yield a clear picture and the exact metabolic consequences are not fully understood.
\end{abstract}

Results: In this work, deletion of the pyk gene, encoding pyruvate kinase, was carried out in the lysine-producing strain $C$. glutamicum lys $\mathrm{C}^{\mathrm{fbr}}$, expressing a feedback resistant aspartokinase, to investigate the cellular response to deletion of this central glycolytic enzyme. Pyk deletion was achieved by allelic replacement, verified by PCR analysis and the lack of in vitro enzyme activity. The deletion mutant showed an overall growth behavior (specific growth rate, glucose uptake rate, biomass yield) which was very similar to that of the parent strain, but differed in slightly reduced lysine formation, increased formation of the overflow metabolites dihydroxyacetone and glycerol and in metabolic fluxes around the pyruvate node. The latter involved a flux shift from pyruvate carboxylase (PC) to PEPC, by which the cell maintained anaplerotic supply of the TCA cycle. This created a metabolic by-pass from PEP to pyruvate via malic enzyme demonstrating its contribution to metabolic flexibility of $C$. glutamicum on glucose.

Conclusion: The metabolic flux analysis performed illustrates the high flexibility of the metabolic network of $C$. glutamicum to compensate for external perturbation. The organism could almost maintain its growth and production performance through a local redirection of the metabolic flux, thereby fulfilling all anabolic and catabolic needs. The formation of the undesired overflow metabolites dihydroxyacetone and glycerol, in the deletion mutant, however, indicates a limiting capacity of the metabolism down-stream of their common precursor glyceraldehyde 3-phosphate and opens possibilities for further strain engineering. 


\section{Background}

The biotechnological production of L-lysine by Corynebacterium glutamicum requires a continuous improvement of the lysine production process with a special focus on optimization of the production strains [1,2]. This includes the identification and implementation of genetic modifications that appear beneficial for production $[3,4]$. In previous work, pyruvate kinase was investigated as genetic target for improved production of lysine [5-7]. This enzyme, catalyzing the irreversible formation of pyruvate from phosphoenolpyruvate (PEP), is a key enzyme in the central pathways of energy production [8]. It is a target for the regulation by metabolites and plays a major role in the rate of energy synthesis, growth and lysine production $[5,9]$. Since pyruvate kinase catalyzes significant flux in $C$. glutamicum [10], its deletion is supposed to reduce the flux into the TCA cycle and the extent of carbon loss via $\mathrm{CO}_{2}$ formation. Moreover, pyruvate kinase-deficient strains can supply the required equimolar ratio of the two lysine precursors oxaloacetate and pyruvate through concerted action of the PTS and PEPC [5]. The deletion of pyruvate kinase in lysine producing strains of C. glutamicum, however, did not yield a clear picture and the exact metabolic consequences are not well characterized. Whereas pyruvate kinase deletion resulted in increased lysine production for different strains of the close relative Brevibacterium flavum $[6,11,12]$, and during the major production phase of a batch process with C. glutamicum [7], production of lysine was strongly reduced in a strain of $C$. lactofermentum [5].

The exact metabolic consequences of deletion of pyruvate kinase in lysine producing C. glutamicum are still not well understood and the topic of the present work. Since single-gene knockouts can be potentially compensated by metabolic flux rerouting through alternative pathways $[13,14]$, we combined quantitative physiological studies with ${ }^{13} \mathrm{C}$ metabolic flux analysis in order to gain a deeper insight into the complex metabolic responses. For this purpose, ${ }^{13} \mathrm{C}$ tracer experiments were combined with GCMS analysis and metabolic and isotopomer balancing for the flux calculation. The potential of such studies for exploration of the central metabolism of C. glutamicum is illustrated from previous studies comparing fluxes in different mutants [15-19], during different phases of a lysine production process [20] or on different carbon sources $[21,22]$. As compared to these previous studies an extended experimental and computational setup was developed and applied here. This included an enlarged metabolic network with separate pools for pyruvate and phosphoenolpyruvate, two parallel tracer studies with $99 \%\left[1-{ }^{13} \mathrm{C}\right]$ and $50 \%\left[{ }^{13} \mathrm{C}_{6}\right]$ glucose and a significantly extended labeling data set with consideration of additional GC-MS fragments. In addition to the previous studies, the extended approach allowed to completely resolve the fine structure of the network around the pyruvate node, which was of special interest in the present work.

\section{Results}

\section{Strain construction and validation}

Deletion of the pyk gene (1428 bp) was obtained by allelic replacement with a shortened DNA fragment containing only the two flanking regions, but not the coding sequence of the gene. The resulting excision of the whole nucleotide sequence of $p y k$ was verified by PCR analysis. Using a site specific primer set of forward and reverse primer (Table 1), the obtained DNA fragment was shortened by about 1500 bp when genomic DNA of lysC $C^{\mathrm{fbr}}$ $\Delta$ pyk was used as template instead of genomic DNA of the reference strain C. glutamicum ATCC 13032.

\section{Pyruvate kinase activity}

C. glutamicum lysC fbr $\Delta$ pyk revealed complete absence of in vitro pyruvate kinase activity $\left(<0.6 \mathrm{mU} \mathrm{mg}^{-1}\right)$, whereas the parent strain C. glutamicum lysC $\mathrm{Cbr}^{\mathrm{fbr}}$ showed a strong specific activity of $1099 \mathrm{mU} \mathrm{mg}^{-1}$ for this enzyme. PCR analysis and in vitro measurement of enzyme activity in crude cell extracts ensured the deletion of the pyk gene and further demonstrated that there is no remaining pyruvate kinase like activity in C. glutamicum lys $\mathrm{C}^{\mathrm{fbr}} \Delta \mathrm{pyk}$. In the deletion strain, direct conversion of PEP into pyruvate thus is restricted to glucose uptake by the PTS.

\section{Influence of pyruvate kinase deletion on growth and production characteristics}

To investigate quantitative physiological effects of the pyruvate kinase deletion, lysine producing C. glutamicum lys $\mathrm{C}^{\mathrm{fbr}}$ and its pyruvate kinase-deficient derivative $C$. glutamicum lys $\mathrm{C}^{\mathrm{fbr}} \Delta \mathrm{pyk}$ were grown in batch culture (Figure 1A-D). While both strains exhibited relatively similar growth characteristics, e.g. concerning specific growth rate, specific glucose uptake rate or biomass yield, yield and specific rate of lysine production appeared to be slightly lower in C. glutamicum lysC fbr $\Delta$ pyk (Table 2, 3).

Table I: Site-specific forward (pyk-F) and reverse (pyk-R) primer sequences used for verification of deletion of the pyk gene encoding pyruvate kinase in C. glutamicum by PCR.

Primer direction

Forward

Reverse
Primer sequence

pyk-F: 5'-GATCC TCGAG CTCTA CTGAG CTGGT TTAT -3'

pyk-R: 5'-GATCG GATCC CGGTC AACAT AGAGC TCA -3' 

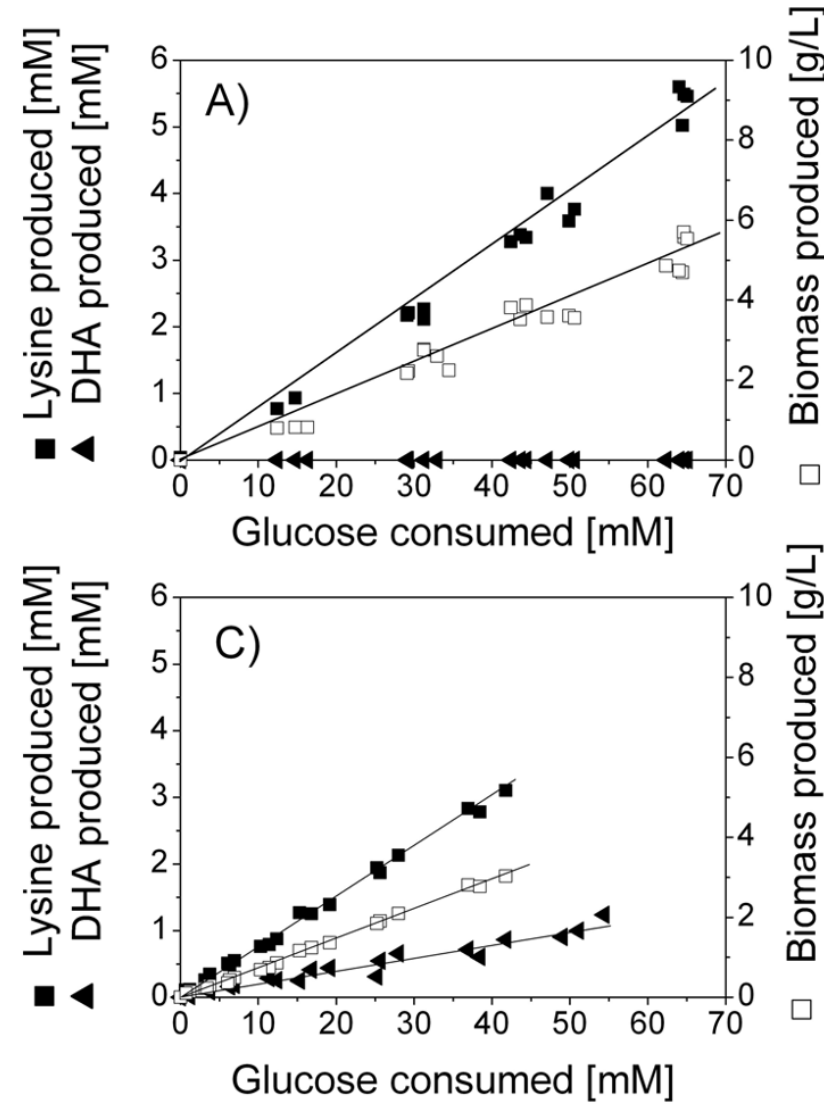
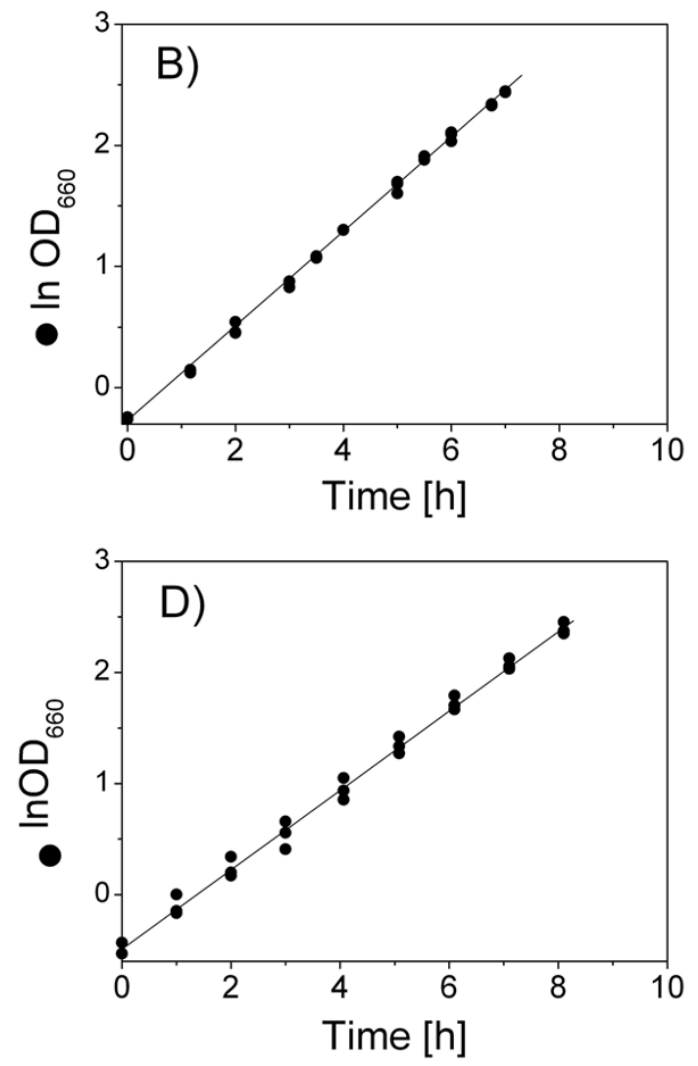

Figure I

Quantitative physiological characteristics of lysine producing C. glutamicum lys $C^{\text {fbr }}$ (A, B) and lysC fbr $\Delta$ pyk (C, D) in batch culture on glucose. The linear correlation between growth, production of lysine and dihydroxyacetone (DHA) and consumption of glucose indicates metabolic steady-state during the cultivation.

Table 2: Growth and production stoichiometry of lysine producing C. glutamicum ATCC 13032 lysC fbr and lysC fbr $\Delta$ pyk during batch cultivation on glucose.

\begin{tabular}{ccc}
\hline Yield & lysC fbr & lysC ${ }^{\text {fbr }} \Delta$ pyk \\
\hline$Y_{\text {X/Glc }}[\mathrm{g} / \mathrm{mol}]$ & $82.1 \pm 1.5$ & $77.1 \pm 0.2$ \\
\hline$Y_{\text {Lys/Glc }}[\mathrm{mmol} / \mathrm{mol}]$ & $82.0 \pm 2.9$ & $73.9 \pm 0.9$ \\
$Y_{\mathrm{DHA} / \mathrm{Glc}}[\mathrm{mmol} / \mathrm{mol}]$ & $0.0 \pm 0.0$ & $20.8 \pm 1.4$ \\
$Y_{\text {Gly/Glc }}[\mathrm{mmol} / \mathrm{mol}]$ & $0.0 \pm 0.0$ & $6.2 \pm 1.3$ \\
$Y_{\text {Tre/Glc }}[\mathrm{mmol} / \mathrm{mol}]$ & $9.1 \pm 0.4$ & $2.9 \pm 0.1$ \\
$Y_{\text {Lac/Glc }}[\mathrm{mmol} / \mathrm{mol}]$ & $6.9 \pm 0.6$ & $7.5 \pm 0.0$
\end{tabular}

The data given are biomass yield $\left(\mathrm{Y}_{\mathrm{X} / \mathrm{S}}\right)$, lysine yield $\left(\mathrm{Y}_{\text {Lys/S }}\right)$ and yields on by-products glycerol $\left(\mathrm{Y}_{\mathrm{Gly} / \mathrm{S}}\right)$, dihydroxyacetone $\left(\mathrm{Y}_{\mathrm{DHA} / \mathrm{S}}\right)$, trehalose $\left(Y_{\text {Tre/S }}\right)$ and lactate $\left(Y_{\text {Lac/S }}\right)$. The yields were determined as slope of the linear fit between biomass or product formation, respectively, and substrate consumption (compare Figures IA and IC). The values given here represent the mean value from three parallel cultivation experiments with corresponding deviations.
Moreover, lack of pyruvate kinase activity resulted in the formation of the overflow metabolites dihydroxyacetone (DHA) and glycerol whereas these compounds were not produced by the parent strain. Trehalose formation was slightly reduced. No significant difference was observed concerning the secretion of lactate which, however, was formed only in very low amount. Major kinetic and stoichiometric parameters, including specific growth rate or yield for biomass, lysine and by-products remained constant throughout the cultivation (Figure 1A - D). This clearly shows that both strains were in metabolic steadystate. In this context, the dissolved oxygen level was above $20 \%$ throughout the whole cultivation so that sufficient oxygen supply for the cells was ensured. The $\mathrm{pH}$ remained constant in a range of $7.0 \pm 0.2$. 
Table 3: Growth and production kinetics of lysine producing $C$. glutamicum ATCC 13032 lys $C^{\mathrm{fbr}}$ and lys $C^{\mathrm{fbr}} \Delta$ pyk during batch cultivation on glucose.

\begin{tabular}{lcc}
\hline Rates & lys $C^{\text {fbr }}$ & lysC fbr $\Delta$ pyk \\
\hline$\mu[\mathrm{I} / \mathrm{h}]$ & $0.38 \pm 0.00$ & $0.35 \pm 0.00$ \\
$\mathrm{q}_{\mathrm{Glc}}[\mathrm{mmol} / \mathrm{g} / \mathrm{h}]$ & $4.60 \pm 0.08$ & $4.50 \pm 0.01$ \\
$\mathrm{q}_{\mathrm{Lys}}[\mathrm{mmol} / \mathrm{g} / \mathrm{h}]$ & $0.38 \pm 0.02$ & $0.33 \pm 0.00$ \\
\hline
\end{tabular}

The specific growth rate was estimated as slope from the semi logarithmic plot of cell concentration versus time (Figures IB and D). The specific glucose uptake rate $\left(q_{G \mid c}\right)$ was calculated from the specific growth rate $(\mu)$ and the biomass yield (Table 2 ). The specific lysine production rate $\left(q_{L y S}\right)$ was calculated from $q_{G \mid c}$ and the lysine yield (Table 2). The values given here represent the mean value from three parallel cultivation experiments with corresponding deviations.

\section{Experimental design for metabolic flux analysis}

In the present work, complete resolution of the fluxes through the different carboxylating and decarboxylating enzymes, i.e. PEPC, PC, phosphoenolpyruvate carboxykinase (PEPCK) and malic enzyme, was required, in order to study the exact influence of the pyruvate kinase deletion to these closely linked reactions. First, the metabolic network of $C$. glutamicum was extended by considering PEP and pyruvate as separate pools and PEPC, PC, PEPCK and malic enzyme as separate metabolic reactions. For this scenario, a previous approach utilizing labeling data from a single tracer study with $\left[1-{ }^{13} \mathrm{C}\right]$ glucose for $C$. glutamicum was significantly extended, since this is not capable to completely resolve all these fluxes, but provides lumped carboxylation and decarboxylation flux [17]. Concerning the central metabolic pathways, $\left[1-{ }^{13} \mathrm{C}\right]$ glucose is valuable for resolving the upper part of metabolism, in particular the oxidative PP pathway, glycolysis and the Entner-Doudoroff pathway, whereas the use of a mixture of $\left[{ }^{13} \mathrm{C}_{6}\right]$ glucose and unlabeled glucose is particularly useful to resolve fluxes downstream of PEP, especially at the pyruvate node $[23,24]$. Due to this the experimental strategy was based on two parallel tracer studies with (i) $\left[1-{ }^{13} \mathrm{C}\right]$ glucose and (ii) a mixture of $\left[{ }^{13} \mathrm{C}_{6}\right]$ glucose and unlabeled glucose to combine the information content available from the GC-MS labelling analysis of metabolites from the different tracer substrates for the flux calculation. Since it is known, that more detailed information for flux calculation can be obtained with GCMS via additional analysis of fragment ions which contain only specific parts of the carbon skeleton of the analyte, we additionally considered a number of fragment ions from the proteinogenic amino acids which have previously proven useful for flux analysis in complex metabolic networks of prokaryotes [25] and eukaryotes [26]. Overall, 197 different mass isotopomer fractions were considered here for each strain, whereas the original simplified approach with only one single tracer experiment and less fragments measured considered only 29 mass isotopomer fractions. The extended approach was tested by computer based simulation studies to see, weather the additionally considered labeling information can be utilized to determine the additionally introduced free fluxes around the pyruvate node. For this purpose, sensitivities for the available mass isotopomer fractions and the flux parameters of interest were derived from partial derivatives as previously described [24]. The labeling patterns of a number of newly considered fragment ions were affected by variation of the free fluxes around the pyruvate node and thus contain sensitive information to determine these flux parameters of interest. This is exemplified for the study with $\left[{ }^{13} \mathrm{C}_{6}\right]$ glucose and unlabeled glucose as tracer substrate and variation of the free flux parameters $\Phi_{\text {PEPC }}$ (flux partitioning between PEPC and PC), $\zeta_{\text {PEPC/PEPCK (exchange flux }}$ by PEPC and PEPCK) and $\zeta_{\mathrm{PC} / \mathrm{MAE}}$ (exchange flux by PC and malic enzyme) which strongly influences the labelling pattern of analyzed metabolites (Figure 2). Using synthetic labelling data sets, a unique solution for the free fluxes was obtained in multiple parameter estimations with randomized varied starting values, demonstrating the observability and identifiability of all free fluxes in the network and the suitability of the developed extended approach.

\section{Tracer studies and flux parameter estimation}

Metabolic flux analysis, as applied here, requires a metabolic and isotopic steady-state of the investigated culture. The presence of metabolic steady-state was ensured from the constant growth and production behavior of the two strains (Figures 1A-D). Exemplified for different proteinogenic amino acids from the two parallel tracer studies sampled at different time points of the cultivation, also the ${ }^{13} \mathrm{C}$ labeling patterns of the metabolites remained constant over time (Figure 3). This indicated isotopic steadystate during the cultivation, so that the flux distributions obtained can be taken as representative for each strain covering the whole cultivation period. The calculation of the metabolic fluxes was based on minimizing the deviation between the experimentally measured and the simulated mass isotopomer fractions. The approach comprised metabolic balancing during each step considering stoichiometric data on growth and product formation from three parallel cultivations (Table 2) and on anabolic demand for biomass precursors [27]. Obviously, an excellent fit was achieved (Table 4). The set of intracellular fluxes that gave minimum deviation between experimental and simulated labelling patterns was taken as best estimate for the intracellular flux distribution (Figure 4).

\section{Metabolic flux response to deletion of pyruvate kinase}

The response of lysine producing C. glutamicum to pyruvate kinase deletion was now investigated on the level of metabolic carbon fluxes. It was interesting to see in detail, how C. glutamicum lysC fbr $\Delta$ pyk could compensate for the 


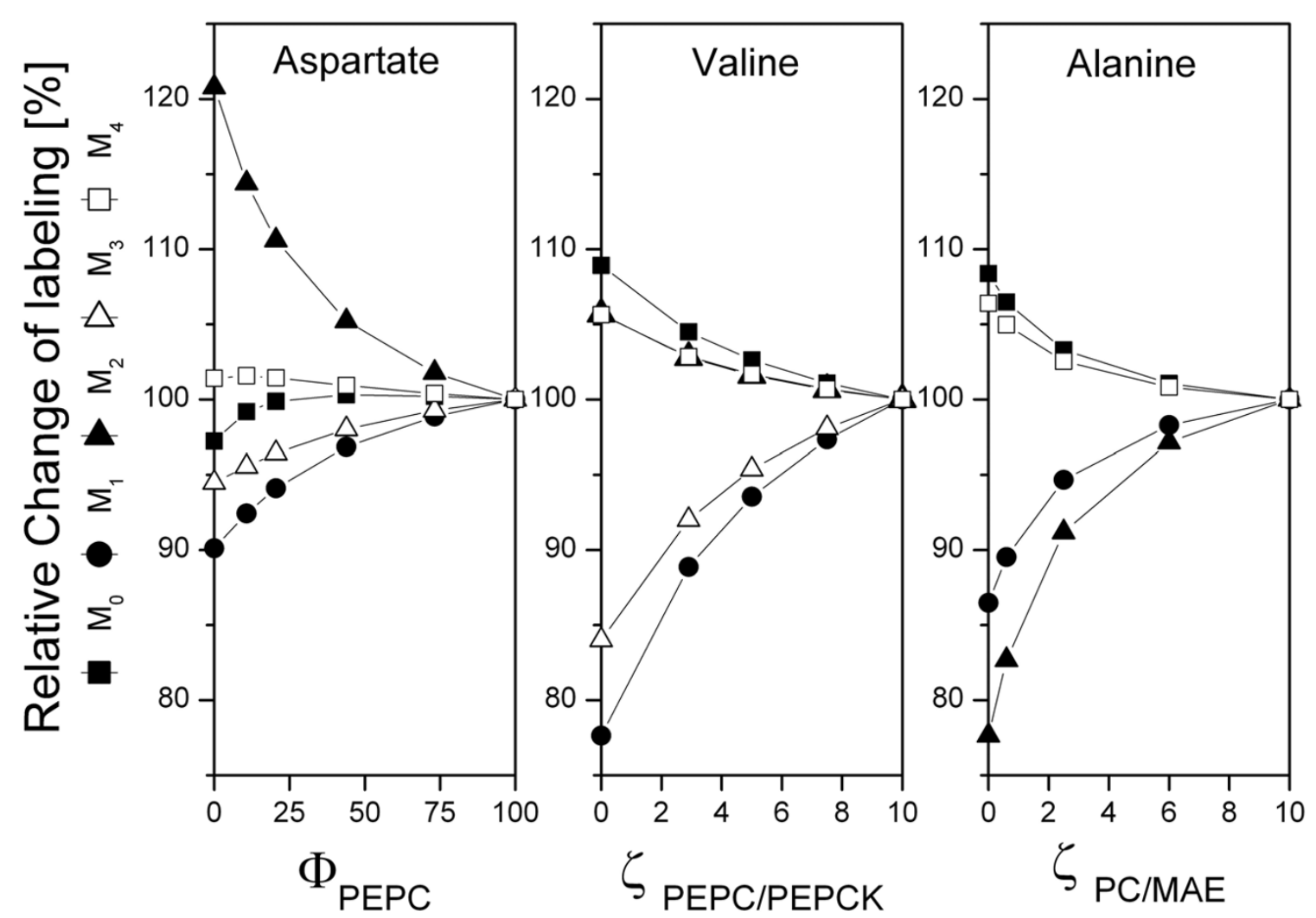

\section{Figure 2}

Experimental design for quantification of flux parameters at the pyruvate node of Corynebacterium glutamicum with an equimolar mixture of $\left[{ }^{13} \mathbf{C}_{6}\right]$ glucose and naturally labelled glucose. Relative change of the mass isotopomer distribution of aspartate $(\mathrm{m} / \mathrm{z} 4 / 8)$ with varied $\Phi_{\text {PEPC }}(A)$, relative change of the mass isotopomer distribution of valine $(\mathrm{m} / \mathrm{z}$ $288)$ with varied $\zeta_{\text {PEPC/PEPCK }}(B)$, relative change of the mass isotopomer distribution of alanine $(\mathrm{m} / \mathrm{z} 260)$ with varied $\zeta_{\mathrm{PC} / \mathrm{MAE}}$ (C). The labelling patterns at sole contribution of PEPC $\left(\Phi_{\mathrm{PEPC}}=100 \%\right)$, and highly reversible fluxes at the pyruvate node $\left(\zeta_{\text {PEPC/PEPCK }}=\zeta_{\text {PC/MAE }}=10\right)$ are taken as reference point and set to $100 \%$. The flux parameters investigated here comprise $\Phi_{\text {PEPC }}$ (flux partitioning between PEPC and PC), $\zeta_{\text {PEPC/PEPCK }}$ (ratio of exchange flux to net flux between the pools of PEP and OAA/MAL catalyzed by PEPC and PEPCK) and $\zeta_{P C / M A E}$ (ratio of exchange flux to net flux between the pools of PYR and OAA/ MAL catalyzed by PC and MAE). The exact definitions for the flux parameters are given in the appendix. Unless varied the flux parameters reflect the situation for the parent strain $C$. glutamicum lys $C^{\text {fbr }}$ (Figure 4).

loss of this central glycolytic gene and almost maintain growth and production characteristics of the parent strain. As direct response to the genetic modification, the overall conversion flux from PEP into pyruvate decreased significantly from $138 \%$ to $100 \%$. The metabolic flux distribution in Figure 4 reveals that the deletion of pyruvate kinase further resulted in local rerouting of the flux around the pyruvate node to by-pass the limited direct conversion from PEP into pyruvate. Responses in the pentose phosphate pathway and the TCA cycle were only rather weak. In detail, the two strains differed significantly in the relative contribution of PC and PEPC to anaplerotic supply of the TCA cycle. Whereas PC was the major anaplerotic enzyme in C. glutamicum lys $\mathrm{C}^{\mathrm{fbr}}$, it was completely inactive in the deletion mutant which rather utilized PEPC for this purpose. The flux through the decarboxylating enzymes PEPCK and malic enzyme showed only slight differences between the two strains. Altogether pyruvate kinase deletion resulted in a strong shift of the anaplerotic net flux from pyruvate to PEP carboxylation 


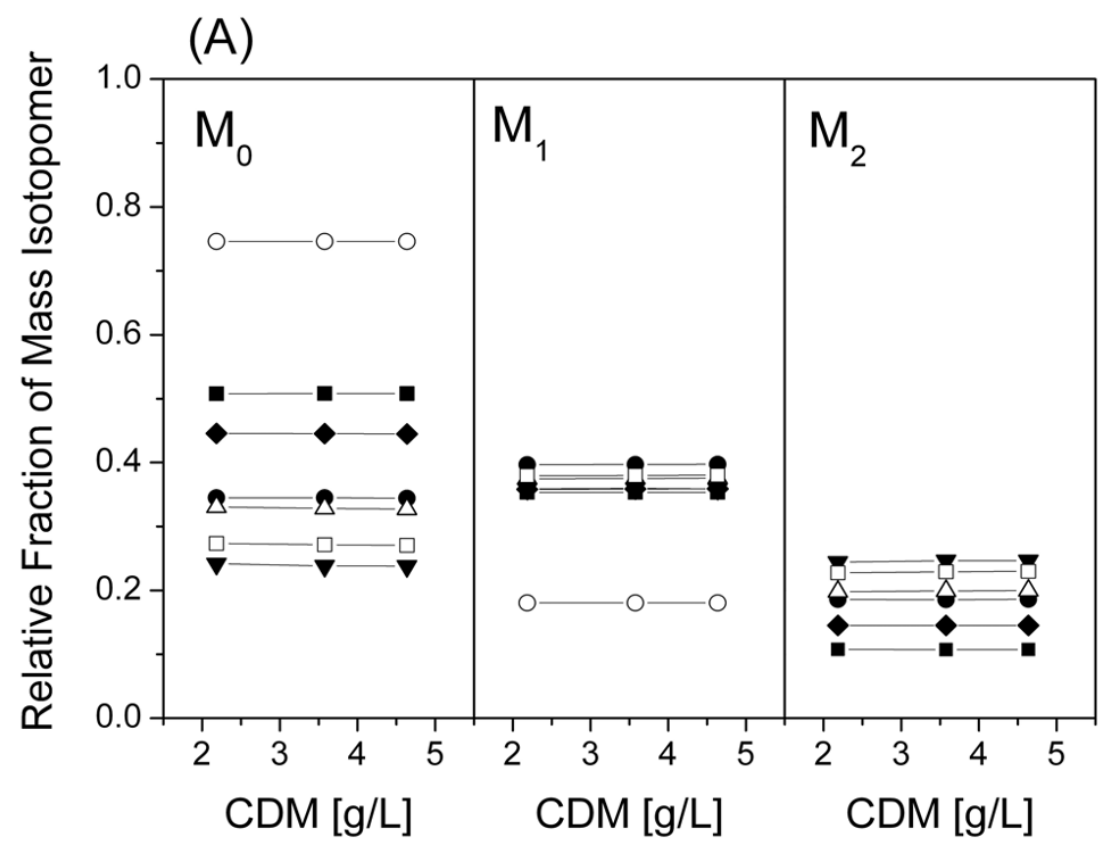

(B)

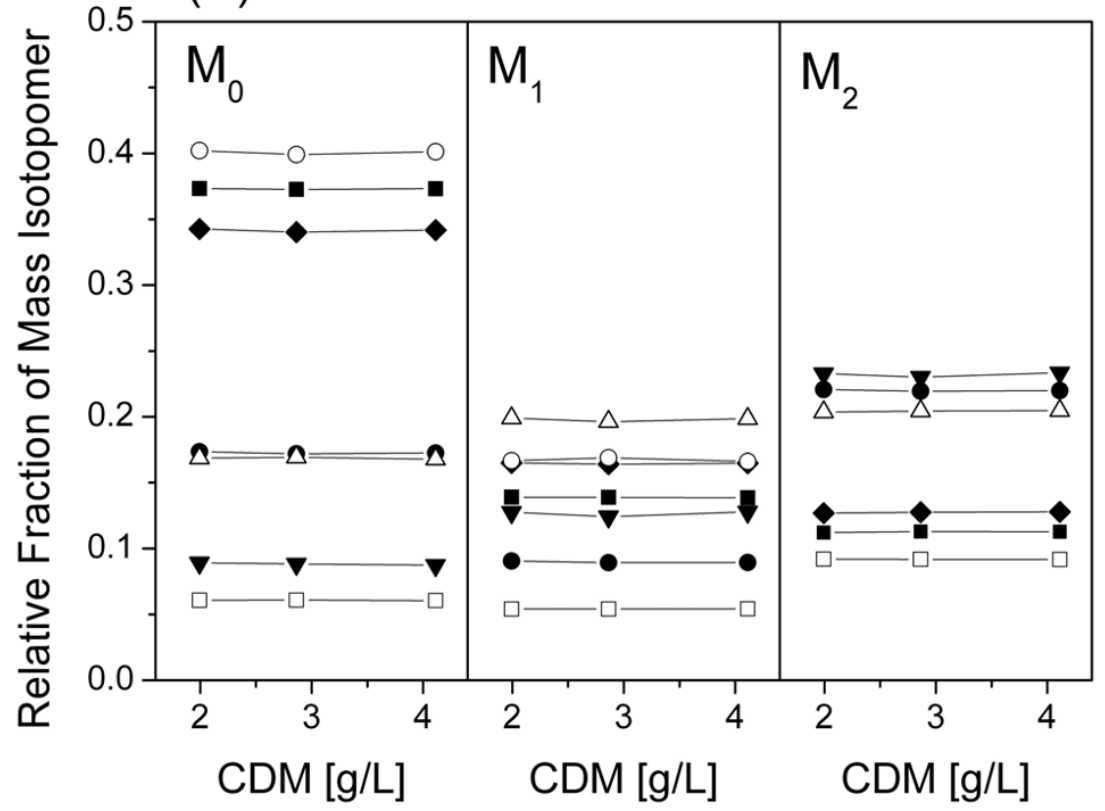

Figure 3

Verification of isotopic steady-state during ${ }^{13} \mathrm{C}$ tracer studies of $C$. glutamicum lys $C^{\mathrm{fbr}} \Delta \mathrm{pyk}$ grown on $\left[\mathrm{I}^{-13} \mathrm{C}\right]$ glucose $(A)$ and an equimolar mixture of $\left[{ }^{13} C_{6}\right]$ glucose and naturally labelled glucose (B). The labelling patterns of the amino acids were determined from protein hydrolysates harvested at different cell dryx mass (CDM) concentrations during the cultivation. The amino acids shown here exemplarily stem form different parts of the metabolic network and comprise alanine (solid square), phenylalanine (open square), valine (closed circle), glycine (open circle), glutamate (closed triangle), threonine (open triangle) and serine (closed diamond). $M_{0}$ (non labelled), $M_{1}$ (single labelled) and $M_{2}$ (double labelled) denote the relative fractions of the corresponding mass isotopomers. 


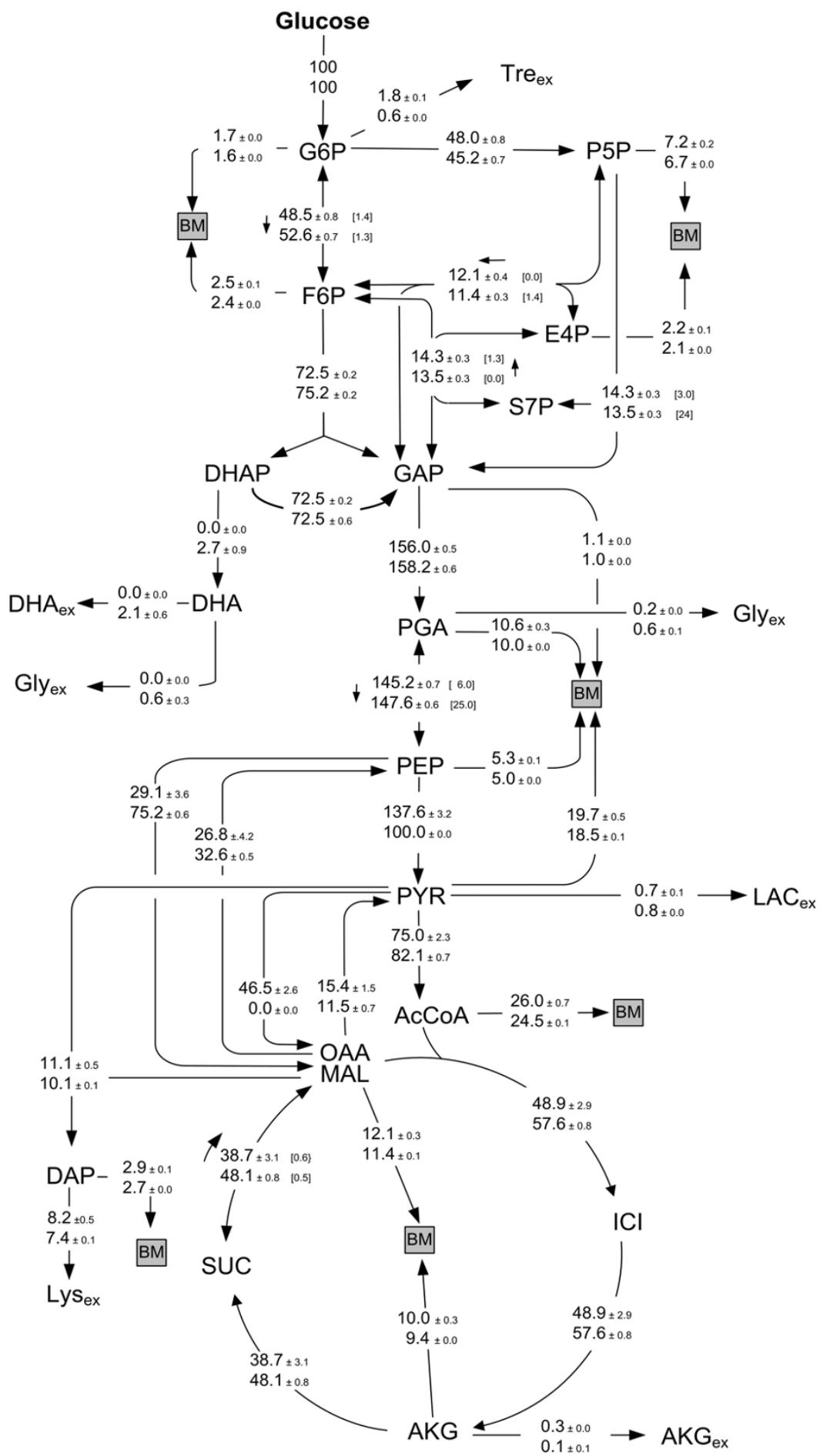

Figure 4

In vivo carbon flux distribution in the central metabolism of lysine producing $C$. glutamicum lys $C$ fbr (top) and its pyruvate kinase deficient derivative $C$. glutamicum lys $C^{\text {fbr }} \Delta$ pyk (bottom) during growth on glucose. All fluxes are given as a molar percentage of the mean specific glucose uptake rate of $\mathrm{q}_{\mathrm{Glc}}=4.6 \mathrm{mmol} \mathrm{g}^{-1} \mathrm{~h}^{-1}$ (for lys $\mathrm{fbr}^{\mathrm{fb}}$ ) and $4.5 \mathrm{mmol}^{-1} \mathrm{~h}^{-1}$ (for lys $C^{f b r} \Delta$ pyk), which is set to $100 \%$. The errors reflect the corresponding $90 \%$ confidence intervals for the different fluxes, obtained by Monte-Carlo analysis. For reversible metabolic reactions, the flux reversibility, i.e. the ratio of exchange flux to net flux, is additionally given in brackets and the direction of the net flux is indicated by an arrow. 
Table 4: Mass isotopomer fractions of amino acids from the cell protein and of secreted trehalose during cultivation of $C$. glutamicum lys $\mathrm{Cbr}^{\mathrm{fb}}$ and lysC fbr $\Delta$ pyk on $99 \%\left[\mathrm{I}-{ }^{13} \mathrm{C}\right]$ glucose and on an equimolar mixture of $99 \%\left[{ }^{13} \mathrm{C}_{6}\right]$ glucose and naturally labelled glucose, respectively.

\begin{tabular}{|c|c|c|c|c|c|c|c|c|c|}
\hline & & \multicolumn{4}{|c|}{ lys $\mathrm{Cfbr}$} & \multicolumn{4}{|c|}{ lys $C^{\text {fbr }} \Delta \mathrm{pyk}$} \\
\hline \multicolumn{2}{|c|}{ Analyte $(\mathrm{m} / \mathrm{z})$} & \multicolumn{2}{|c|}{$\left[1-{ }^{13} \mathrm{C}\right]$ glucose } & \multicolumn{2}{|c|}{$50 \%\left[{ }^{13} \mathrm{C}_{6}\right]$ glucose } & \multicolumn{2}{|c|}{$\left[I^{13} \mathrm{C}\right]$ glucose } & \multicolumn{2}{|c|}{$50 \%\left[{ }^{13} \mathrm{C}_{6}\right]$ glucose } \\
\hline & & $\exp$ & calc & $\exp$ & calc & $\exp$ & calc & $\exp$ & calc \\
\hline \multirow{4}{*}{$\mathrm{Ala}_{260}$} & $M_{0}$ & 0.503 & 0.505 & 0.371 & 0.368 & 0.508 & 0.504 & 0.373 & 0.365 \\
\hline & $M_{1}$ & 0.356 & 0.359 & 0.140 & 0.141 & 0.353 & 0.357 & 0.139 & 0.144 \\
\hline & $M_{2}$ & 0.109 & 0.106 & 0.114 & 0.114 & 0.107 & 0.107 & 0.113 & 0.117 \\
\hline & $M_{3}$ & & & 0.375 & 0.377 & & & 0.376 & 0.375 \\
\hline \multirow[t]{3}{*}{$\mathrm{Ala}_{232}$} & $M_{0}$ & 0.536 & 0.540 & 0.410 & 0.408 & 0.538 & 0.540 & 0.415 & 0.408 \\
\hline & $M_{1}$ & 0.361 & 0.360 & 0.147 & 0.150 & 0.359 & 0.359 & 0.140 & 0.150 \\
\hline & $M_{2}$ & & & 0.443 & 0.442 & & & 0.445 & 0.442 \\
\hline \multirow[t]{6}{*}{$\mathrm{Val}_{288}$} & $M_{0}$ & 0.341 & 0.339 & 0.171 & 0.163 & 0.344 & 0.339 & 0.173 & 0.161 \\
\hline & $M_{1}$ & 0.396 & 0.401 & 0.091 & 0.091 & 0.397 & 0.400 & 0.089 & 0.092 \\
\hline & $M_{2}$ & 0.189 & 0.188 & 0.218 & 0.218 & 0.186 & 0.188 & 0.220 & 0.219 \\
\hline & $M_{3}^{2}$ & & & 0.236 & 0.236 & & & 0.236 & 0.236 \\
\hline & $M_{4}$ & & & 0.107 & 0.111 & & & 0.106 & 0.113 \\
\hline & $M_{5}$ & & & 0.177 & 0.181 & & & 0.177 & 0.180 \\
\hline \multirow[t]{5}{*}{$\mathrm{Val}_{260}$} & $M_{0}$ & 0.354 & 0.354 & 0.186 & 0.180 & 0.353 & 0.354 & 0.188 & 0.179 \\
\hline & $M_{1}$ & 0.400 & 0.403 & 0.095 & 0.097 & 0.399 & 0.402 & 0.093 & 0.097 \\
\hline & $M_{2}$ & 0.181 & 0.180 & 0.378 & 0.379 & 0.182 & 0.180 & 0.385 & 0.378 \\
\hline & $M_{3}$ & & & 0.133 & 0.135 & & & 0.128 & 0.136 \\
\hline & $M_{4}$ & & & 0.208 & 0.209 & & & 0.206 & 0.209 \\
\hline \multirow[t]{5}{*}{$\mathrm{Val}_{186}$} & $M_{0}$ & 0.388 & 0.393 & 0.200 & 0.195 & 0.387 & 0.393 & 0.205 & 0.194 \\
\hline & $M_{1}$ & 0.411 & 0.418 & 0.088 & 0.091 & 0.408 & 0.417 & 0.084 & 0.091 \\
\hline & $M_{2}$ & 0.154 & 0.154 & 0.395 & 0.397 & 0.155 & 0.155 & 0.404 & 0.396 \\
\hline & $M_{3}$ & & & 0.116 & 0.114 & & & 0.109 & 0.115 \\
\hline & $M_{4}$ & & & 0.201 & 0.204 & & & 0.198 & 0.204 \\
\hline \multirow[t]{5}{*}{$\mathrm{Thr}_{404}$} & $M_{0}$ & 0.333 & 0.331 & 0.173 & 0.167 & 0.327 & 0.329 & 0.167 & 0.161 \\
\hline & $M_{1}$ & 0.375 & 0.377 & 0.199 & 0.196 & 0.376 & 0.377 & 0.199 & 0.195 \\
\hline & $M_{2}$ & 0.197 & 0.196 & 0.195 & 0.200 & 0.200 & 0.198 & 0.205 & 0.209 \\
\hline & $\mathrm{M}_{3}$ & & & 0.227 & 0.232 & & & 0.224 & 0.228 \\
\hline & $M_{4}$ & & & 0.206 & 0.205 & & & 0.206 & 0.207 \\
\hline \multirow[t]{4}{*}{$\mathrm{Thr}_{376}$} & $M_{0}$ & 0.372 & 0.371 & 0.198 & 0.198 & 0.366 & 0.370 & 0.194 & 0.192 \\
\hline & $M_{1}$ & 0.378 & 0.380 & 0.251 & 0.249 & 0.380 & 0.380 & 0.256 & 0.252 \\
\hline & $M_{2}$ & 0.184 & 0.183 & 0.298 & 0.297 & 0.187 & 0.184 & 0.296 & 0.296 \\
\hline & $M_{3}$ & & & 0.253 & 0.256 & & & 0.254 & 0.260 \\
\hline \multirow[t]{5}{*}{$\mathrm{Asp}_{418}$} & $M_{0}$ & 0.328 & 0.331 & 0.171 & 0.167 & 0.324 & 0.328 & 0.167 & 0.161 \\
\hline & $M_{1}$ & 0.374 & 0.376 & 0.197 & 0.196 & 0.374 & 0.376 & 0.200 & 0.195 \\
\hline & $M_{2}$ & 0.200 & 0.197 & 0.195 & 0.200 & 0.202 & 0.198 & 0.205 & 0.209 \\
\hline & $\mathrm{M}_{3}$ & & & 0.228 & 0.232 & & & 0.223 & 0.229 \\
\hline & $M_{4}$ & & & 0.209 & 0.205 & & & 0.205 & 0.207 \\
\hline \multirow[t]{4}{*}{$\operatorname{Asp}_{390}$} & $M_{0}$ & 0.370 & 0.371 & 0.200 & 0.198 & 0.364 & 0.369 & 0.195 & 0.192 \\
\hline & $M_{1}$ & 0.376 & 0.379 & 0.250 & 0.248 & 0.379 & 0.379 & 0.256 & 0.252 \\
\hline & $M_{2}$ & 0.185 & 0.184 & 0.294 & 0.297 & 0.188 & 0.184 & 0.293 & 0.296 \\
\hline & $M_{3}$ & & & 0.255 & 0.257 & & & 0.256 & 0.260 \\
\hline \multirow[t]{3}{*}{$\operatorname{Asp}_{316}$} & $M_{0}$ & 0.405 & 0.408 & 0.214 & 0.212 & 0.398 & 0.406 & 0.209 & 0.206 \\
\hline & $M_{1}$ & 0.382 & 0.387 & 0.252 & 0.251 & 0.384 & 0.387 & 0.259 & 0.255 \\
\hline & $M_{2}$ & 0.160 & 0.158 & 0.290 & 0.293 & 0.164 & 0.159 & 0.288 & 0.291 \\
\hline
\end{tabular}


Table 4: Mass isotopomer fractions of amino acids from the cell protein and of secreted trehalose during cultivation of $C$. glutamicum lys $\mathrm{C}^{\mathrm{fbr}}$ and lysC $\mathrm{Cbr}^{\mathrm{fb}} \Delta \mathrm{pyk}$ on $99 \%[\mathrm{I-13} \mathrm{C}]$ glucose and on an equimolar mixture of $99 \%\left[{ }^{13} \mathrm{C}_{6}\right]$ glucose and naturally labelled glucose, respectively. (Continued)

\begin{tabular}{|c|c|c|c|c|c|c|c|c|c|}
\hline & $M_{3}$ & & & 0.244 & 0.244 & & & 0.244 & 0.248 \\
\hline \multirow[t]{6}{*}{$\mathrm{Glu}_{432}$} & $M_{0}$ & $0.24 I$ & 0.245 & 0.090 & 0.087 & 0.238 & 0.244 & 0.087 & 0.084 \\
\hline & $M_{1}$ & 0.358 & 0.366 & 0.127 & 0.124 & 0.359 & 0.365 & 0.128 & 0.125 \\
\hline & $M_{2}$ & 0.245 & 0.242 & 0.230 & 0.233 & 0.246 & 0.242 & 0.233 & 0.231 \\
\hline & $M_{3}$ & & & 0.238 & $0.24 I$ & & & 0.245 & 0.244 \\
\hline & $M_{4}$ & & & 0.183 & 0.185 & & & 0.180 & 0.185 \\
\hline & $M_{5}$ & & & 0.132 & 0.130 & & & 0.127 & 0.132 \\
\hline \multirow[t]{5}{*}{$\mathrm{Glu}_{330}$} & $M_{0}$ & 0.335 & 0.331 & 0.156 & 0.147 & 0.334 & 0.330 & 0.155 & 0.144 \\
\hline & $M_{1}$ & 0.396 & 0.398 & 0.140 & 0.141 & 0.393 & 0.397 & 0.141 & 0.146 \\
\hline & $M_{2}$ & 0.193 & 0.194 & 0.336 & 0.336 & 0.195 & 0.196 & 0.340 & 0.332 \\
\hline & $M_{3}$ & & & 0.178 & 0.185 & & & 0.179 & 0.190 \\
\hline & $M_{4}$ & & & 0.189 & 0.191 & & & 0.185 & 0.189 \\
\hline \multirow[t]{4}{*}{$\mathrm{Ser}_{390}$} & $M_{0}$ & 0.443 & 0.443 & 0.344 & 0.345 & 0.445 & 0.442 & 0.342 & 0.342 \\
\hline & $M_{1}$ & 0.361 & 0.362 & 0.162 & 0.163 & 0.359 & 0.361 & 0.165 & 0.165 \\
\hline & $M_{2}$ & 0.145 & 0.145 & 0.123 & 0.123 & 0.145 & 0.146 & 0.128 & 0.127 \\
\hline & $M_{3}$ & & & 0.371 & 0.369 & & & 0.366 & 0.366 \\
\hline \multirow[t]{3}{*}{$\mathrm{Ser}_{362}$} & $M_{0}$ & 0.478 & 0.480 & 0.383 & 0.386 & 0.478 & 0.480 & 0.382 & 0.385 \\
\hline & $M_{1}$ & 0.375 & 0.375 & 0.169 & 0.170 & 0.375 & 0.374 & 0.174 & 0.171 \\
\hline & $M_{2}$ & & & 0.448 & 0.445 & & & 0.444 & 0.444 \\
\hline \multirow[t]{3}{*}{$\mathrm{Ser}_{288}$} & $M_{0}$ & 0.519 & 0.521 & 0.407 & 0.407 & 0.520 & 0.521 & 0.405 & 0.406 \\
\hline & $M_{1}$ & 0.368 & 0.368 & 0.151 & 0.149 & 0.368 & 0.368 & 0.154 & 0.150 \\
\hline & $M_{2}$ & & & 0.443 & 0.444 & & & 0.440 & 0.443 \\
\hline \multirow[t]{10}{*}{$\mathrm{Phe}_{336}$} & $M_{0}$ & 0.277 & 0.271 & 0.060 & 0.057 & 0.271 & 0.268 & 0.060 & 0.057 \\
\hline & $M_{1}$ & 0.382 & 0.386 & 0.054 & 0.052 & 0.380 & 0.383 & 0.054 & 0.052 \\
\hline & $M_{2}$ & 0.225 & 0.230 & 0.093 & 0.091 & 0.230 & 0.231 & 0.092 & 0.091 \\
\hline & $M_{3}$ & & & 0.144 & 0.137 & & & 0.142 & 0.137 \\
\hline & $M_{4}$ & & & 0.144 & 0.141 & & & 0.142 & 0.141 \\
\hline & $M_{5}$ & & & 0.142 & 0.141 & & & 0.140 & 0.142 \\
\hline & $M_{6}$ & & & 0.143 & 0.145 & & & 0.144 & 0.146 \\
\hline & $M_{7}$ & & & 0.102 & 0.107 & & & 0.103 & 0.107 \\
\hline & $M_{8}$ & & & 0.059 & 0.063 & & & 0.061 & 0.063 \\
\hline & $M_{9}$ & & & 0.060 & 0.066 & & & 0.061 & 0.065 \\
\hline \multirow[t]{9}{*}{$\mathrm{Phe}_{234}$} & $M_{0}$ & 0.311 & 0.313 & 0.072 & 0.069 & 0.306 & 0.309 & 0.073 & 0.069 \\
\hline & $M_{1}$ & 0.405 & 0.409 & 0.057 & 0.055 & 0.403 & 0.408 & 0.057 & 0.056 \\
\hline & $M_{2}$ & 0.209 & 0.208 & 0.157 & 0.157 & 0.212 & 0.210 & 0.157 & 0.156 \\
\hline & $M_{3}$ & & & 0.129 & 0.123 & & & 0.129 & 0.124 \\
\hline & $M_{4}$ & & & 0.176 & 0.175 & & & 0.173 & 0.175 \\
\hline & $M_{5}$ & & & 0.126 & 0.124 & & & 0.128 & 0.125 \\
\hline & $M_{6}$ & & & 0.153 & 0.160 & & & 0.154 & 0.159 \\
\hline & $M_{7}$ & & & 0.062 & 0.065 & & & 0.063 & 0.065 \\
\hline & $M_{8}^{\prime}$ & & & 0.068 & 0.073 & & & 0.067 & 0.072 \\
\hline \multirow[t]{3}{*}{$\mathrm{Phe}_{302}$} & $M_{0}$ & 0.712 & 0.711 & 0.402 & 0.389 & 0.709 & 0.708 & 0.395 & 0.388 \\
\hline & $M_{1}$ & 0.209 & 0.210 & 0.182 & 0.178 & 0.210 & 0.212 & 0.184 & 0.181 \\
\hline & $M_{2}$ & & & 0.416 & 0.432 & & & 0.422 & 0.432 \\
\hline \multirow[t]{2}{*}{$\mathrm{Gly}_{246}$} & $M_{0}$ & 0.747 & 0.743 & 0.403 & 0.399 & 0.746 & 0.738 & 0.401 & 0.398 \\
\hline & $M_{1}$ & 0.180 & 0.184 & 0.164 & 0.164 & 0.180 & 0.188 & 0.166 & 0.167 \\
\hline \multirow[t]{2}{*}{$\mathrm{Gly}_{218}$} & $M_{0}$ & 0.822 & 0.821 & 0.432 & 0.436 & 0.822 & 0.818 & 0.433 & 0.435 \\
\hline & $M_{1}$ & 0.178 & 0.179 & 0.467 & 0.463 & 0.178 & 0.182 & 0.467 & 0.463 \\
\hline
\end{tabular}


Table 4: Mass isotopomer fractions of amino acids from the cell protein and of secreted trehalose during cultivation of $C$. glutamicum lys $\mathrm{C}^{\mathrm{fbr}}$ and lys $\mathrm{C}^{\mathrm{fbr}} \Delta$ pyk on $99 \%\left[\mathrm{I}^{-13} \mathrm{C}\right]$ glucose and on an equimolar mixture of $99 \%\left[{ }^{13} \mathrm{C}_{6}\right]$ glucose and naturally labelled glucose, respectively. (Continued)

\begin{tabular}{|c|c|c|c|c|c|c|c|c|c|}
\hline \multirow[t]{9}{*}{$\mathrm{Tyr}_{466}$} & $M_{0}$ & 0.239 & 0.234 & 0.533 & 0.537 & 0.234 & 0.231 & 0.533 & 0.537 \\
\hline & $M_{1}$ & 0.355 & 0.360 & 0.053 & 0.050 & 0.354 & 0.357 & 0.053 & 0.049 \\
\hline & $M_{2}$ & 0.242 & 0.247 & 0.053 & 0.051 & 0.246 & 0.248 & 0.054 & 0.051 \\
\hline & $\mathrm{M}_{3}$ & & & 0.089 & 0.087 & & & 0.088 & 0.086 \\
\hline & $M_{4}$ & & & 0.136 & 0.130 & & & 0.134 & 0.131 \\
\hline & $M_{5}$ & & & 0.142 & 0.140 & & & 0.140 & 0.140 \\
\hline & $M_{6}$ & & & 0.142 & 0.143 & & & 0.142 & 0.143 \\
\hline & $M_{7}$ & & & 0.146 & 0.146 & & & 0.146 & 0.147 \\
\hline & $M_{8}$ & & & 0.109 & 0.113 & & & 0.109 & 0.113 \\
\hline \multirow{3}{*}{$\mathrm{Tyr}_{302}$} & $M_{0}$ & 0.716 & 0.711 & 0.067 & 0.071 & 0.714 & 0.708 & 0.069 & 0.072 \\
\hline & $M_{1}$ & 0.206 & 0.210 & 0.062 & 0.068 & 0.208 & 0.212 & 0.064 & 0.068 \\
\hline & $M_{2}$ & & & 0.397 & 0.389 & & & 0.395 & 0.388 \\
\hline \multirow[t]{7}{*}{$\operatorname{Arg}_{442}$} & $M_{0}$ & 0.199 & 0.195 & 0.050 & 0.049 & 0.187 & 0.193 & 0.048 & 0.046 \\
\hline & $M_{1}$ & 0.332 & 0.341 & 0.105 & 0.106 & 0.328 & 0.340 & 0.118 & 0.105 \\
\hline & $M_{2}$ & 0.257 & 0.267 & 0.183 & 0.183 & 0.265 & 0.268 & 0.174 & 0.180 \\
\hline & $\mathrm{M}_{3}^{2}$ & & & 0.233 & 0.232 & & & 0.217 & 0.232 \\
\hline & $M_{4}$ & & & 0.207 & 0.204 & & & 0.199 & 0.206 \\
\hline & $M_{5}$ & & & 0.146 & 0.149 & & & 0.157 & 0.151 \\
\hline & $M_{6}$ & & & 0.075 & 0.078 & & & 0.087 & 0.080 \\
\hline \multirow[t]{3}{*}{$\operatorname{Tre}_{361}$} & $M_{0}$ & 0.060 & 0.061 & & & 0.062 & 0.063 & & \\
\hline & $M_{1}$ & 0.592 & 0.613 & & & 0.598 & 0.614 & & \\
\hline & $M_{2}$ & 0.214 & 0.204 & & & 0.210 & 0.202 & & \\
\hline
\end{tabular}

The data comprise experimental GC-MS data (exp) and values predicted by the solution of the mathematical model corresponding to the optimized set of fluxes (calc). The latter were corrected for the presence of natural isotopes $[42,43]$ to directly match the experimental data. $M_{0}$ represents the amount of non-labelled mass isotopomer fraction, $M_{1}$ the amount of singly-labelled mass isotopomer fraction and corresponding terms refer to a higher labelling.
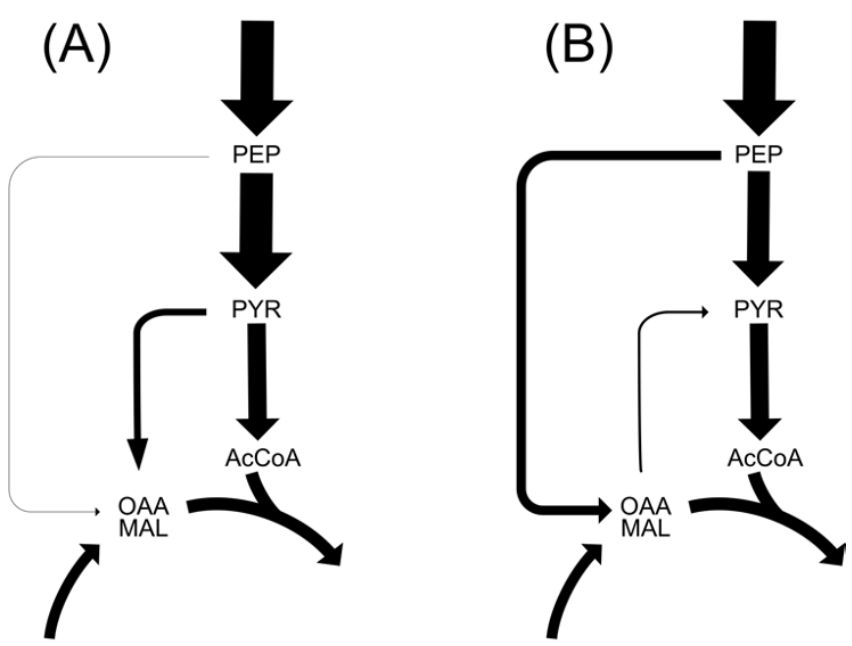

Figure 5

Carbon net flux distribution at the pyruvate node of lysine producing $C$. glutamicum lys $C^{\text {fbr }}$ (left) and its pyruvate kinase deficient derivative $C$. glutamicum lys Cfbr $\Delta$ pyk (right) cultivated on glucose. The actual flux values are represented by the thickness of the corresponding arrows. and created a metabolic by-pass from PEP via oxaloacetate and malate towards pyruvate involving PEPC, malate dehydrogenase and malic enzyme (Figure 5). This by-pass enabled a sufficient supply of pyruvate so that a high flux through pyruvate dehydrogenase and TCA cycle was maintained. Overall, C. glutamicum lys $\mathrm{C}^{\mathrm{fbr}} \Delta \mathrm{pyk}$ could compensate for the gene deletion by local flux readjustment involving flexible utilization of its anaplerotic enzymes. The narrow confidence intervals underline that all carbon fluxes were estimated with very high precision (Figure 4). The flux differences discussed here are therefore clearly related to the deletion of pyruvate kinase. Since the specific glucose uptake rate was almost identical for the two strains (Table 3), all conclusions drawn for the relative fluxes also hold for the absolute flux values.

\section{Discussion}

In the present work the physiological responses of lysine producing C. glutamicum to deletion of the central glycolytic enzyme pyruvate kinase were studied. As shown, the pyruvate kinase deficient mutant showed slightly reduced lysine production, but could almost maintain the growth characteristics of the parent strain. The most striking consequence of pyruvate kinase deletion was a rearrangement 
of the fluxes through the anaplerotic reactions, i.e. a flux shift from PC to PEPC. This local flux rerouting in the deletion mutant created a metabolic by-pass via PEPC, malate dehydrogenase and malic enzyme. The conversion of oxaloacetate into malate as part of this by-pass is in the reverse direction of the net TCA cycle flux, rather forming oxaloacetate form malate, and would require a reversible inter conversion of these two metabolites. The metabolic network model applied here considers malate and oxaloacetate as a single pool, i.e. fully equilibrated labeling exchange between the two pools. The excellent fit of the labeling data thus supports the presence of a reversible inter conversion between malate and oxaloacetate. Further evidence comes from in vitro studies in C. glutamicum demonstrating the reversible inter conversion of malate and oxaloacetate by concerted action of the cytoplasmatic $(\mathrm{MDH})$ and the membrane bound malate dehydrogenase (MDH) [28]. The activation of this by-pass is the key to compensate for the loss of pyruvate kinase activity and maintain the flux through the TCA cycle as well as through other central pathways including PPP, glycolysis or anabolism. The same metabolic by-pass is also activated in pyruvate kinase deficient $E$. coli during growth on glucose $[13,29]$ and obviously displays a general strategy of microorganisms possessing both, PEPC and PC. In contrast, $B$. subtilis lacking PEPC cannot grow on glucose in the absence of pyruvate kinase [30,31]. Both strains exhibited significant flux through malic enzyme demonstrating the important role of this enzyme for the flexibility of the $C$. glutamicum metabolism. In the deletion mutant, malic enzyme is part of the metabolic by-pass created and thus contributes to the robustness of the metabolism against perturbation of the carbon flux. Its flux, i.e. its in vivo activity, in both strains shows that it also plays an important role for the flexibility of the cofactor metabolism in C. glutamicum. In the examined strains, lysine production is decoupled from feedback regulation thereby posing an increased demand for NADPH on the metabolism. As shown by the NADPH balance, malic enzyme is required to meet the cellular NADPH demand and contributes significantly to the supply of this cofactor (Figure 6). Previous studies already assumed such a physiological role e.g. during growth on fructose [32] or during lysine production [17]. The lower flux through malic enzyme as well as through the PPP in the pyruvate kinase deletion strain might be related to the increased flux through isocitrate dehydrogenase, resulting in enhanced NADPH supply via the TCA cycle. A co-regulation of NADPH supplying pathways, balancing the overall supply has been previously observed in lysine producing C. glutamicum [18].

The exact effect of deletion of pyruvate kinase on lysine production in C. glutamicum obviously depends on the production strain as well as on cultivation conditions. Whereas, upon deletion of pyruvate kinase, lysine produc- tion was enhanced in different strains of B. flavum $[6,11]$, decreasing production was observed in C. lactofermentum [5] and, to some extent, also in the present work. Since the overall supply of NADPH did not significantly change, a possible explanation might be a limited availability of the lysine precursor oxaloacetate. The physiological characteristics and the intracellular carbon fluxes of C. glutamicum lys $\mathrm{C}^{\mathrm{fbr}}$ and C. glutamicum lysC $\mathrm{C}^{\mathrm{fbr}} \Delta \mathrm{pyk}$, studied here, point at possible explanations. In this regard the accumulation of dihydroxyacetone and glycerol, specifically related to deletion of pyruvate kinase, appears interesting. These over flow metabolites are formed by C. glutamicum, when the flux entering into the lower glycolytic chain exceeds the capacity of reactions down-stream of glyceraldehyde 3 -phosphate, e.g. during growth on fructose [21,32]. Under these conditions the bottleneck is attributed to glyceraldehyde 3-phosphate dehydrogenase and caused by an unfavorable ratio of NAD/NADH reducing the capacity of this enzyme. The glyceraldehyde 3-phosphate dehydrogenase flux, however, was not different between the two strains studied here, which does not support a contribution of this enzyme to the observed limitation. Other candidates appear more likely. As shown, the anaplerotic flux is completely shifted to PEPC in the deletion mutant. Compared to the parent strain, the overall flux through this enzyme is increased about 2.5 fold which could display the maximum capacity this enzyme can handle under these conditions. In this regard, strains of $C$. glutamicum, previously showing enhanced lysine production upon pyruvate kinase deletion, additionally contained a feedback-resistant variant of PEPC, insensitive to allosteric control by aspartate [11], whereas a double mutant, lacking pyruvate kinase and PEPC, exhibited seriously impaired glucose utilization [7]. It appears also possible that limited capacity of malic enzyme is involved in the observed limitation. Malic enzyme activity in the pyruvate kinase deficient wild type of C. glutamicum is not sufficient to enable growth on acetate or citrate, but growth can be restored by over expression of this enzyme [33].

\section{Conclusion}

The present work is an evident example, that metabolic flux analysis is a powerful strategy for detailed quantitative investigation of production strains in order to obtain detailed understanding of the cellular response to genetic changes. The flux analysis performed illustrates the high flexibility of the metabolic network of C. glutamicum to compensate for external perturbation. The formation of the undesired overflow metabolites dihydroxyacetone and glycerol, in the deletion mutant, however, indicates a limiting capacity of the metabolism down-stream of their common precursor glyceraldehyde 3-phosphate and opens possibilities for further strain engineering. Based on the results of this study, over expression or de-regulation 


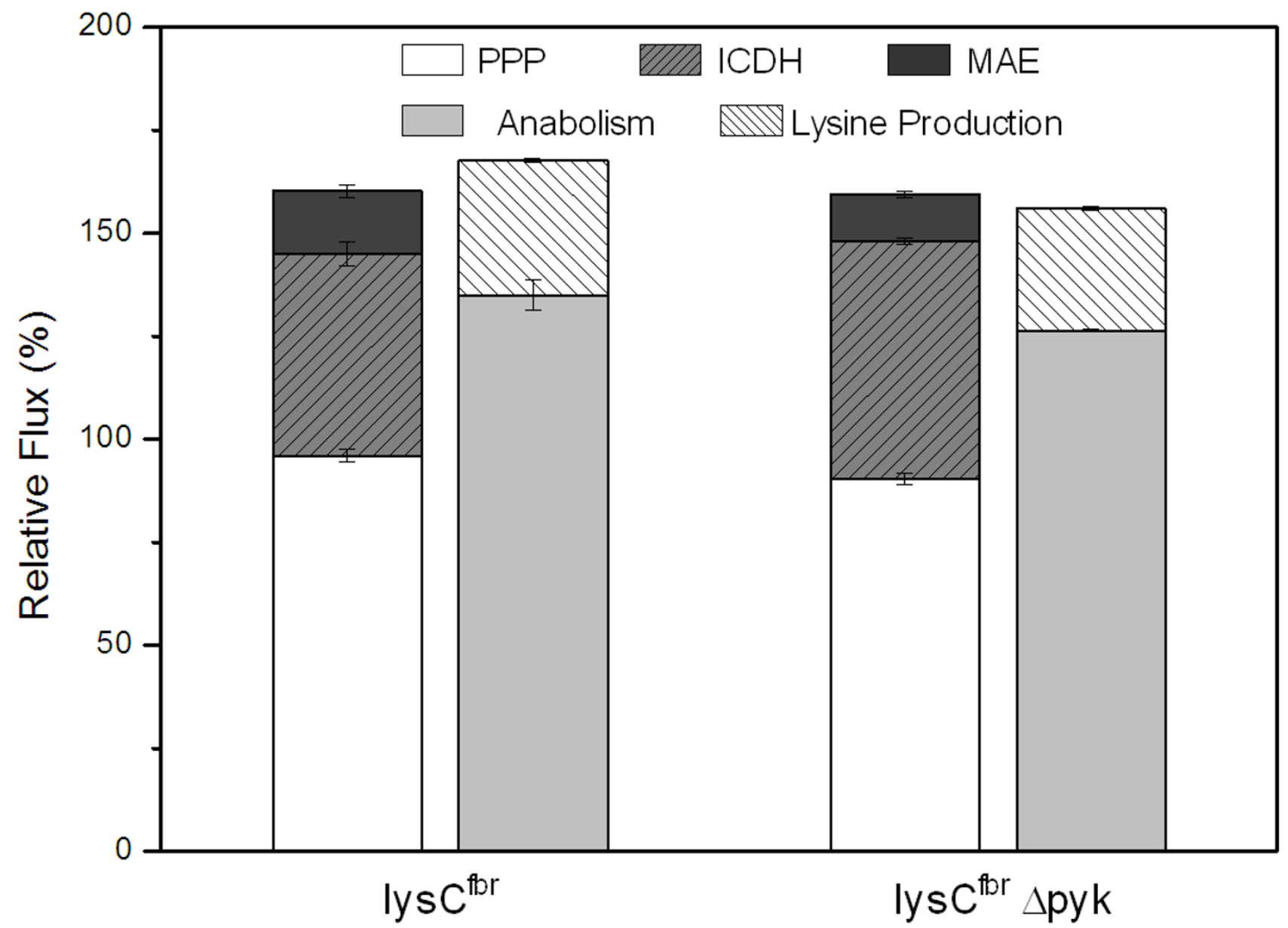

Figure 6

NADPH balance for $C$. glutamicum lys $C^{\mathrm{fbr}}$ (left) and its pyruvate kinase deficient derivative $C$. glutamicum lys $C^{\text {fbr }} \Delta$ pyk (right) considering glucose 6-phosphate dehydrogenase and 6-phosphogluconate dehydrogenase (PPP), isocitrate dehydrogenase (ICDH) and malic enzyme (MAE) as NADPH supplying reactions. Anabolism with a stoichiometric demand of 16.4 mmol NAPDH (g cell dry weight) ${ }^{-1}$ [27] and lysine production with a stoichiometric demand of 4 mol NADPH (mol lysine) ${ }^{-1}$ were considered as NADPH consuming reactions.

of PEPC in a pyruvate kinase negative production strain appear promising to overcome the formation of dihydroxyacetone and glycerol and enhance lysine production via increased supply of oxaloacetate.

\section{Methods}

\section{Microorganisms}

The reference strain C. glutamicum ATCC 13032 was derived from the American Type and Culture Collection (Manassas, USA). Deregulated lysine production through a feedback resistant aspartokinase was previously achieved by introduction of the point mutation T311I in the lys $\mathrm{C}$ gene ( $\mathrm{NCgl0247}$ ) leading to the lysine producing mutant Corynebacterium glutamicum lys $\mathrm{C}^{\mathrm{fbr}}[16]$. In the present work, pyruvate kinase was additionally deleted through allelic replacement of the pyk gene ( $\mathrm{NCgl2008),}$ resulting in the pyruvate kinase deficient mutant $C$. glutamicum lys $\mathrm{C}^{\mathrm{fbr}} \Delta \mathrm{pyk}$. The primer sequences used for verification of $p y k$ deletion are given in Table 1.

\section{Media}

Complex medium containing $5 \mathrm{~g} \mathrm{~L}^{-1}$ glucose, $5 \mathrm{~g} \mathrm{~L}^{-1}$ yeast extract, $10 \mathrm{~g} \mathrm{~L}^{-1}$ tryptone, $5 \mathrm{~g} \mathrm{~L}^{-1} \mathrm{NaCl}$ and $18 \mathrm{~g} \mathrm{~L}^{-1}$ agar was used for agar plates. First pre-cultures were grown in the same medium without agar. Second pre-cultivation and main cultivation was performed in minimal medium with $80 \mathrm{mM}$ glucose as carbon source. The minimal medium additionally contained per liter: $0.055 \mathrm{~g} \mathrm{CaCl}_{2} \cdot 2 \mathrm{H}_{2} \mathrm{O}, 0.2$

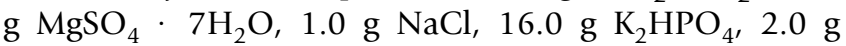
$\mathrm{KH}_{2} \mathrm{PO}_{4}, 5.0 \mathrm{~g}\left(\mathrm{NH}_{4}\right)_{2} \mathrm{SO}_{4}, 0.5 \mathrm{mg}$ biotin, $1 \mathrm{mg}$ Ca-pan- 
thothenic acid, $1 \mathrm{mg}$ thiamine $\cdot \mathrm{HCl}, 20 \mathrm{mg} \mathrm{FeSO}, 30 \mathrm{mg}$ 3,4-dihydroxybenzoic acid and $10 \mathrm{ml}$ of a $100 \times$ trace element solution [34]. In tracer experiments for metabolic flux analysis, naturally labeled glucose was replaced by 99 $\%\left[1-{ }^{13} \mathrm{C}\right]$ glucose or by an equimolar mixture of naturally labeled and $99 \%\left[{ }^{13} \mathrm{C}_{6}\right]$ glucose.

\section{Cultivation}

Single colonies from agar plates incubated for $24 \mathrm{~h}$ at $30^{\circ} \mathrm{C}$ were used to inoculate the first pre-culture which was grown for $8 \mathrm{~h}$ in $500 \mathrm{~mL}$ baffled shake flasks with 50 $\mathrm{mL}$ complex medium. Subsequently, cells were harvested by centrifugation $\left(8,800 \times \mathrm{g}, 2 \mathrm{~min}, 4^{\circ} \mathrm{C}\right)$, washed with sterile $0.9 \% \mathrm{NaCl}$, and used as inoculum for the second pre-culture $(50 \mathrm{ml}$ minimal medium in $500 \mathrm{~mL}$ baffled shake flasks). Physiological studies comprised three replicate cultivations for quantification of growth and production characteristics $(500 \mathrm{ml}$ baffled shake flasks with 50 mL minimal medium) and two parallel tracer cultivations with ${ }^{13} \mathrm{C}$ labeled glucose $(100 \mathrm{~mL}$ flasks with $10 \mathrm{~mL}$ medium) for each strain. All cultures were inoculated with exponentially growing cells from the second pre-culture and incubated at $30^{\circ} \mathrm{C}$ and $230 \mathrm{rpm}$ on a rotary shaker (shaking diameter $5 \mathrm{~cm}$, Multitron, Infors AG, Bottmingen, Switzerland). During cultivation, dissolved oxygen concentration was monitored via immobilized sensor spots on the flask bottom containing a fluorophor with oxygen dependent luminescent decay time [35].

\section{Chemicals}

Yeast extract and tryptone were obtained from Difco Laboratories (Detroit, USA). Ninety-nine \% [1-13C] glucose and $99 \%\left[{ }^{13} \mathrm{C}_{6}\right]$ glucose were purchased from Campro Scientific (Veenendaal, The Netherlands). All other chemicals were purchased from Sigma, Merck (Darmstadt, Germany), or Fluka (Buchs, Switzerland) and were of analytical grade.

\section{Substrate and product analysis}

Samples taken during the cultivation were analyzed for concentrations of biomass, substrates and products. Cell concentration was determined by measurement of the optical density at $660 \mathrm{~nm}$ (Novaspec II, Pharmacia Biotech, Little Chalfont, UK). If necessary, samples were diluted on an analytical balance (CP255D, Sartorius, Göttingen, Germany) to obtain absorbance values below 0.3. The correlation factor between cell dry mass (CDM) and optical density was determined as $\mathrm{CDM}=0.382 \times \mathrm{OD}$ (gram per litre) for C. glutamicum lysC $\mathrm{C}^{\mathrm{fbr}}$ and $0.393 \times \mathrm{OD}$ (gram per litre) for C. glutamicum lys $C^{\mathrm{fbr}} \Delta \mathrm{pyk}$. For the analysis of extracellular substrates and products, cultivation supernatant was obtained by centrifugation of $1 \mathrm{~mL}$ broth $(5 \mathrm{~min}, 16.000 \times \mathrm{g}$, Biofuge Fresco, Heraeus Instruments, Hanau, Germany). Concentration of glucose, trehalose, glycerol, dihydroxyacetone (DHA) and organic acids was quantified in 1:10-diluted cultivation supernatant by HPLC (Kontron Instruments, Neufahrn, Germany). Separation was carried out on an Aminex HPX$87 \mathrm{H}$ column $(300 \times 7.8 \mathrm{~mm}$; Bio- $\mathrm{Rad}$, Hercules, USA $)$ at $45^{\circ} \mathrm{C}$ with $5 \mathrm{mM} \mathrm{H}_{2} \mathrm{SO}_{4}$ as mobile phase and a flow rate of $0.5 \mathrm{ml} \mathrm{min}^{-1}$. Refraction index (sugars, glycerol) and UV absorption at $210 \mathrm{~nm}$ (organic acids, DHA) was used for detection. Amino acid quantification in cultivation supernatant was performed as described previously [36].

\section{Pyruvate kinase assay}

Crude cell extract was prepared as described previously [37]. Cell debris was removed by centrifugation $(9,800 \times$ $\mathrm{g}, 2 \times 30 \mathrm{~min}, 4^{\circ} \mathrm{C}$ ) and the obtained supernatant was used for determination of pyruvate kinase activity and protein content by the method of Bradford [38]. Enzyme activity was determined as described by Netzer et al. [33]. The reaction was carried out in a total volume of $1 \mathrm{ml}$ at pH 7.0 containing $100 \mathrm{mM}$ Tris/ $\mathrm{HCl}, 15 \mathrm{mM} \mathrm{MgCl}_{2}, 1$ $\mathrm{mM}$ ADP, $0.25 \mathrm{mM} \mathrm{NADH}, 5.5 \mathrm{U}$ of lactate dehydrogenase, $10 \mathrm{mM}$ PEP and $10 \mu \mathrm{l}$ of the crude cell extract. Negative controls were carried out without PEP or without cell extract, respectively.

\section{Mass spectrometric labeling analysis}

Mass isotopomer fractions of amino acids from hydrolyzed and lyophilized cell protein and of trehalose from lyophilized culture supernatant, harvested during the exponential phase from the tracer studies, were determined by GC-MS $[19,39]$. Sample preparation and measurement was performed as described previously [16]. The mean experimental error for the mass isotopomer fractions measured in triplicate was about $0.4 \%$.

\section{Metabolic network and biomass requirements}

The metabolic network of C. glutamicum comprised all central metabolic pathways, i. e. glycolysis, PPP and TCA cycle [16]. In C. glutamicum, pyruvate carboxylase (PC), PEP carboxylase (PEPC), malic enzyme (MAE) and phosphoenolpyruvate carboxykinase (PEPCK) link glycolysis and TCA cycle through inter conversion of $\mathrm{C}_{3}$ and $\mathrm{C}_{4}$ metabolites [40]. In contrast to previous work, where carboxylation and decarboxylation, respectively, were only regarded as lumped fluxes all single enzymes were considered as separate reactions. For this purpose, PEP and pyruvate were considered as separate metabolic pools. Additionally the pathways for the biosynthesis of lysine and different by-products and the anabolic pathways from intermediary precursors into biomass were implemented. For glycine synthesis two possible routes were considered, i.e. via serine and via threonine aldolase [41]. Enzymatic steps regarded reversible were transaldolase and transketolase, phosphoglucose isomerase, the reactions of the lower glycolytic chain interconnecting PEP and 3-phosphoglycerate and of the TCA cycle intercon- 
necting succinate and oxaloacetate. The precursor demand for biomass formation was taken from the biomass composition and the corresponding pathway stoichiometry of C. glutamicum [27]. For the pyruvate kinase deletion strain, the flux converting PEP into pyruvate was set equal to the glucose uptake flux. This was justified from the fact that no pyruvate kinase-like activity remained in this strain, so that the direct conversion of PEP into pyruvate was restricted to the glucose PTS.

\section{Estimation of metabolic flux}

Metabolic flux distribution of C. glutamicum was determined by minimizing the deviation between the experimental and simulated GC-MS mass isotopomer fractions using a metabolic model implemented in Matlab 7.0 (Mathworks Inc., Nattick, USA) on a personal computer with isotopomer and metabolite balancing and the solver fmincon implemented in Matlab as previously described [18]. Hereby, the labelling data simulated by the isotopomer model were corrected for natural isotopes $[42,43]$. The parameter estimation involved two parallel metabolic networks for calculation of the ${ }^{13} \mathrm{C}$ label distribution in order to consider the labelling data from both parallel tracer experiments in the same parameter optimization. The network was over determined. A least square approach was therefore possible. As error criterion a weighted sum of least squares (SLS) was used. For both strains, identical flux distributions were obtained with multiple randomized initialization values for the free flux parameters, suggesting that global minima were identified. Statistical analysis of the obtained fluxes was carried out by a Monte-Carlo approach [18]. From the obtained data $90 \%$ confidence limits for the single parameters were calculated.

\section{Appendix}

Flux partitioning ratio $(\Phi)$ and flux reversibility $(\zeta)$ were defined as relative flux into one of the two branches, and as ratio of backward or exchange flux to the net flux in the forward direction, respectively [18]. For the pyruvate node with the reactions catalyzed by phosphoenolpyruvate carboxylase (PEPC), pyruvate carboxylase (PC), phosphoenolpyruvate carboxykinase (PEPCK), and malic enzyme (MAE) the definitions were as follows:

$$
\begin{aligned}
\Phi_{\mathrm{PEPC}} & =\frac{v_{\mathrm{PEPC}}}{v_{\mathrm{PEPC}}+v_{\mathrm{PC}}} \\
\zeta_{\mathrm{PEPC} / \mathrm{PECK}} & =\frac{v_{\mathrm{PEPCK}}}{v_{\mathrm{PEPC}}-v_{\mathrm{PEPCK}}} \\
\zeta_{\mathrm{PC} / \mathrm{MAE}} & =\frac{v_{\mathrm{MAE}}}{v_{\mathrm{PC}}-v_{\mathrm{MAE}}}
\end{aligned}
$$

\section{Competing interests}

The author(s) declare that they have no competing interests.

\section{Authors' contributions}

Construction of the $p y k$ deletion mutant was carried out by CK. JB performed the experimental studies of the present work, i.e. the physiological studies for determination of growth and production characteristics, the enzymatic analysis and the ${ }^{13} \mathrm{C}$ tracer studies including GC/MS labeling analysis. CW carried out the modeling work including design and validation of the extended approach, metabolic modeling, parameter estimation and statistical analysis. The manuscript was drafted by CW and JB.

\section{Acknowledgements}

This work was supported by BASF AG (Ludwigshafen, Germany).

\section{References}

I. Kelle R, Hermann T, Bathe B: L-Lysine Production. In Handbook of Corynebacterium glutamicum Edited by: Eggeling L, Bott M. Boca Raton, CRC Press; 2005:465-488.

2. Wittmann C, Becker J: The I-lysine story: From metabolic pathways to industrial production. In Microbiology Monographs Springer Berlin/ Heidelberg ; 2007.

3. Takors R, Bathe B, Rieping M, Hans S, Kelle R, Huthmacher K: Systems biology for industrial strains and fermentation processes--example: amino acids. J Biotechnol 2007, I 29(2): |8|-| 90.

4. Wendisch VF, Bott M, Eikmanns BJ: Metabolic engineering of Escherichia coli and Corynebacterium glutamicum for biotechnological production of organic acids and amino acids. Curr Opin Microbiol 2006, 9(3):268-274.

5. Gubler M, Jetten M, Lee SH, Sinskey AJ: Cloning of the pyruvate kinase gene (pyk) of Corynebacterium glutamicum and sitespecific inactivation of pyk in a lysine-producing Corynebacterium lactofermentum strain. Appl Environ Microbiol 1994, 60(7):2494-2500.

6. Ozaki A, Shiio I: Production of lysine by pyruvate kinase mutants of Brevibacterium flavum. Agric Biol Chem 1983, 47:1569-1576.

7. Park SM, Sinskey AJ, Stephanopoulos G: Metabolic and Physiological Studies of Corynebacterium glutamicum Mutants. Biotechnol Bioeng 1997, 55:864-879.

8. Jetten M, Pitoc GA, Follettie MT, Sinskey AJ: Regulation of phospho(enol)-pyruvate- and oxaloacetate-converting enzymes in Corynebacterium glutamicum. Appl Microbiol Biotechnol I 994 , 4I:47-52.

9. Ozaki H, Shiio I: Regulation of the TCA and glyoxylate cycles in Brevibacterium flavum. II. Regulation of phosphoenolpyruvate carboxylase and pyruvate kinase. J Biochem (Tokyo) 1969, 66(3):297-3II.

10. Shirai T, Fujimura K, Furusawa C, Nagahisa K, Shioya S, Shimizu H: Study on roles of anaplerotic pathways in glutamate overproduction of Corynebacterium glutamicum by metabolic flux analysis. Microb Cell Fact 2007, 6:19.

II. Shiio I, Yokota A, Sugimoto S: Effect of Pyruvate Kinase Deficiency on L-Lysine Productivities of Mutants with Feedbackresistant Aspartokinases. Agric Biol Chem 1987, 5 I:2485-2493.

12. Shiio I, Yoshino H, Sugimoto S: Isolation and properties of lysineproducing mutants with feedback-resistant aspartokinase derived from a Brevibacterium flavum strain with citrate synthase and pyruvate kinase-defects and feedback-resistant phosphoenolpyruvate carboxylase. Agric Biol Chem 1990, 54:3275-3282.

13. Emmerling M, Dauner M, Ponti A, Fiaux J, Hochuli M, Szyperski T, Wuthrich K, Bailey JE, Sauer U: Metabolic flux responses to pyruvate kinase knockout in Escherichia coli. J Bacteriol 2002, 184(I): 152-164. 
14. Fischer E, Sauer U: Metabolic flux profiling of Escherichia coli mutants in central carbon metabolism using GC-MS. Eur J Biochem 2003, 270(5):880-89I.

15. Becker J, Klopprogge C, Herold A, Zelder O, Bolten CJ, Wittmann C: Metabolic flux engineering of I-lysine production in Corynebacterium glutamicum - over expression and modification of G6P dehydrogenase. J Biotechnol 2007.

16. Becker J, Klopprogge C, Zelder O, Heinzle E, Wittmann C: Amplified expression of fructose I,6-bisphosphatase in Corynebacterium glutamicum increases in vivo flux through the pentose phosphate pathway and lysine production on different carbon sources. Appl Environ Microbiol 2005, 7I(1 2):8587-8596.

17. Kim HM, Heinzle E, Wittmann C: Deregulation of aspartokinase by single nucleotide exchange leads to global flux rearrangement in the central metabolism of Corynebacterium glutamicum. I Microbiol Biotechnol 2006, in press:

18. Wittmann C, Heinzle E: Genealogy profiling through strain improvement by using metabolic network analysis: metabolic flux genealogy of several generations of lysine-producing corynebacteria. Appl Environ Microbiol 2002, 68(12):5843-5859.

19. Wittmann C, Kim HM, Heinzle E: Metabolic network analysis of lysine producing Corynebacterium glutamicum at a miniaturized scale. Biotechnol Bioeng 2004, 87(I): I-6.

20. Krömer JO, Sorgenfrei O, Klopprogge K, Heinzle E, Wittmann C: Indepth profiling of lysine-producing Corynebacterium glutamicum by combined analysis of the transcriptome, metabolome, and fluxome. J Bacteriol 2004, I 86(6): I 769-I 784.

21. Kiefer P, Heinzle E, Zelder O, Wittmann C: Comparative metabolic flux analysis of lysine-producing Corynebacterium glutamicum cultured on glucose or fructose. Appl Environ Microbiol 2004, 70(I):229-239.

22. Wittmann C, Kiefer P, Zelder O: Metabolic fluxes in Corynebacterium glutamicum during lysine production with sucrose as carbon source. Appl Environ Microbiol 2004, 70( I 2):7277-7287.

23. Fischer E, Zamboni N, Sauer U: High-throughput metabolic flux analysis based on gas chromatography-mass spectrometry derived I3C constraints. Anal Biochem 2004, 325(2):308-316.

24. Wittmann C, Heinzle E: Modeling and experimental design for metabolic flux analysis of lysine-producing Corynebacteria by mass spectrometry. Metab Eng 200I, 3(2): I73-191.

25. Klapa MI, Aon JC, Stephanopoulos G: Systematic quantification of complex metabolic flux networks using stable isotopes and mass spectrometry. Eur J Biochem 2003, 270(I 7):3525-3542.

26. Frick $O$, Wittmann $C$ : Characterization of the metabolic shift between oxidative and fermentative growth in Saccharomyces cerevisiae by comparative I3C flux analysis. Microb Cell Fact 2005, 4:30.

27. Wittmann C, de Graaf A: Metabolic flux analysis in Corynebacterium glutamicum. In Handbook of Corynebacterium glutamicum Edited by: Eggeling L, Bott M. Boca Raton, CRC Press; 2005:277-304.

28. Molenaar D, van der Rest ME, Drysch A, Yucel R: Functions of the membrane-associated and cytoplasmic malate dehydrogenases in the citric acid cycle of Corynebacterium glutamicum. A Bacteriol 2000, I 82(24):6884-689I.

29. Al Zaid Siddiquee K, Arauzo-Bravo MJ, Shimizu K: Metabolic flux analysis of pykF gene knockout Escherichia coli based on I3C-labeling experiments together with measurements of enzyme activities and intracellular metabolite concentrations. Appl Microbiol Biotechnol 2004, 63(4):407-4I7.

30. Diesterhaft MD, Freese E: Role of pyruvate carboxylase, phosphoenolpyruvate carboxykinase, and malic enzyme during growth and sporulation of Bacillus subtilis. I Biol Chem 1973, 248(I 7):6062-6070.

31. Fry B, Zhu T, Domach MM, Koepsel RR, Phalakornkule C, Ataai MM: Characterization of growth and acid formation in a Bacillus subtilis pyruvate kinase mutant. Appl Environ Microbiol 2000, 66(9):4045-4049.

32. Dominguez H, Rollin C, Guyonvarch A, Guerquin-Kern JL, CocaignBousquet M, Lindley ND: Carbon-flux distribution in the central metabolic pathways of Corynebacterium glutamicum during growth on fructose. Eur J Biochem 1998, 254(I):96-102.

33. Netzer R, Krause M, Rittmann D, Peters-Wendisch PG, Eggeling L, Wendisch VF, Sahm H: Roles of pyruvate kinase and malic enzyme in Corynebacterium glutamicum for growth on car- bon sources requiring gluconeogenesis. Arch Microbiol 2004, I 82(5):354-363.

34. Vallino JJ, Stephanopoulos G: Metabolic flux distributions in Corynebacterium glutamicum during growth and lysine overproduction. Reprinted from Biotechnology and Bioengineering, Vol. 4I, Pp 633-646 (1993). Biotechnol Bioeng 2000, 67(6):872-885.

35. Wittmann C, Kim HM, John G, Heinzle E: Characterization and application of an optical sensor for quantification of dissolved O2 in shake-flasks. Biotechnol Lett 2003, 25(5):377-380.

36. Krömer JO, Fritz M, Heinzle E, Wittmann C: In vivo quantification of intracellular amino acids and intermediates of the methionine pathway in Corynebacterium glutamicum. Anal Biochem 2005, 340(I): $171-173$.

37. Becker J, Klopprogge C, Herold A, Zelder O, Bolten CJ, Wittmann C Metabolic flux engineering of I-lysine production in Corynebacterium glutamicum-over expression and modification of G6P dehydrogenase. J Biotechnol 2007.

38. Bradford MM: A rapid and sensitive method for the quantitation of microgram quantities of protein utilizing the principle of protein-dye binding. Anal Biochem 1976, 72:248-254.

39. Kiefer P, Heinzle E, Wittmann C: Influence of glucose, fructose and sucrose as carbon sources on kinetics and stoichiometry of lysine production by Corynebacterium glutamicum. J Ind Microbiol Biotechnol 2002, 28(6):338-343.

40. Petersen S, de Graaf AA, Eggeling L, Mollney M, Wiechert W, Sahm $H$ : In vivo quantification of parallel and bidirectional fluxes in the anaplerosis of Corynebacterium glutamicum. J Biol Chem 2000, 275(46):35932-3594I.

4I. Simic P, Willuhn J, Sahm H, Eggeling L: Identification of glyA (encoding serine hydroxymethyltransferase) and its use together with the exporter ThrE to increase L-threonine accumulation by Corynebacterium glutamicum. Appl Environ Microbiol 2002, 68(7):332I-3327.

42. van Winden WA, Wittmann C, Heinzle E, Heijnen JJ: Correcting mass isotopomer distributions for naturally occurring isotopes. Biotechnol Bioeng 2002, 80(4):477-479.

43. Wittmann C, Heinzle $E$ : Mass spectrometry for metabolic flux analysis. Biotechnol Bioeng 1999, 62(6):739-750.

Publish with Bio Med Central and every scientist can read your work free of charge

"BioMed Central will be the most significant development for disseminating the results of biomedical research in our lifetime. "

Sir Paul Nurse, Cancer Research UK

Your research papers will be:

- available free of charge to the entire biomedical community

- peer reviewed and published immediately upon acceptance

- cited in PubMed and archived on PubMed Central

- yours - you keep the copyright
BioMedcentral 